\title{
The dual role of Escherichia coli in the course of ulcerative colitis
}

\author{
Magdalena Pilarczyk-Zurek, Magdalena Strus ${ }^{1 *}$, Pawel Adamski ${ }^{2}$ and Piotr B. Heczko ${ }^{1}$
}

\begin{abstract}
Background: This study examines the dual role of Escherichia coli in the course of ulcerative colitis (UC). The intestinal microbiota is considered to play an important role in UC pathogenesis, but how $E$. coli contributes to inflammation in UC is still unknown. On the one hand, we demonstrated that there was a significant increase in the number of $E$. coli at the sites of inflammation in patients with UC, which can lead to immune system activation, whilst, on the other hand, E. coli may contribute to the resolution of inflammatory reactions since E. coli can inhibit hydroxyl radical formation by eliminating substrates of the Fenton reaction, by assimilating ferrous iron $\left(\mathrm{Fe}^{2+}\right)$ and inducing the decomposition of hydrogen peroxide $\left(\mathrm{H}_{2} \mathrm{O}_{2}\right)$. On this way, E. coli may affect the initiation and/or prolongation of remission stages of UC.

Methods: Ten E. coli strains were isolated from the colonic mucosa of patients in the acute phase of UC. Using PCR, we examined the presence of genes encoding catalases ( $k a t G$ and $k a t E$ ) and proteins participating in iron acquisition (feoB, fepA, fhuA, fecA, iroN, fyuA, and iutA) in these $E$. coli strains. To determine if iron ions influence the growth rate of $E$. coli and its ability to decompose $\mathrm{H}_{2} \mathrm{O}_{2}$, we grew $E$. coli in defined culture media without iron (M9(-)) or with ferrous ions $\left(\mathrm{M} 9\left(\mathrm{Fe}^{2+}\right)\right)$. Expression levels of genes encoding catalases were examined by real-time PCR.

Results: All investigated E. coli strains had catalase genes ( $k a t G, k a t E)$, genes coding for receptors for Fe ${ }^{2+}$ $(f e o B)$ and at least one of the genes responsible for iron acquisition related to siderophores (fepA, fhuA, fec $A$, iroN, fyuA, iutA). E. coli cultured in $\mathrm{M} 9\left(\mathrm{Fe}^{2+}\right)$ grew faster than E. coli in $\mathrm{M} 9(-)$. The presence of $\mathrm{Fe}^{2+}$ in the media contributed to the increased rate of $\mathrm{H}_{2} \mathrm{O}_{2}$ decomposition by $E$. coli and induced kat $G$ gene expression.

Conclusions: E. coli eliminates substrates of the Fenton reaction by assimilating $\mathrm{Fe}^{2+}$ and biosynthesizing enzymes that catalyze $\mathrm{H}_{2} \mathrm{O}_{2}$ decomposition. Thus, E. coli can inhibit hydroxyl radical formation, and affects the initiation and/or prolongation of remission stages of UC.
\end{abstract}

Keywords: Ulcerative colitis, Escherichia coli, Ferrous acquisition, Catalases

\section{Background}

Ulcerative colitis (UC) is a chronic non-specific inflammatory disease characterized by inflammation that is limited to the mucosa of the colon and rectum. The characteristic symptoms of UC are bloody diarrhea and abdominal pain. Clinically, the course of UC commonly consists of periods of exacerbated inflammations and remissions. Disease activity is determined on the basis of medical history and endoscopic changes in the colon $[1,2]$. Genetic predisposition, disorders of the immune system, environmental

\footnotetext{
*Correspondence: mbstrus@cyf-kr.edu.pl

'Department of Microbiology, Jagiellonian University Medical College, Czysta

18 Street, 31-121 Cracow, Poland

Full list of author information is available at the end of the article
}

factors, and the intestinal microbiota are the primary factors contributing to the etiology of UC [3]. Currently, the intestinal microbiota is considered to play an important role in UC pathogenesis $[4,5]$. E. coli has been specifically highlighted for its role in the propagation and maintenance of chronic inflammation in UC. The biology of $E$. coli suggests that it may play a double role and show the ability both to increase or decrease gut inflammation. For example, high levels of E. coli gut colonization are correlated with high concentrations of its lipopolysaccharide, which activates the host immune system. However, E. coli also has features that can promote the resolution of intestinal inflammation $[6,7]$. 
In the exacerbation stage of UC, the action of an increased number of reactive oxygen species (ROS) intensifies necrosis of the intestinal epithelium. One of the most active forms of ROS is the hydroxyl radical $\left(\mathrm{OH}^{-}\right)$, which is a product of the Fenton reaction.

Fenton reaction: $\mathrm{Fe}^{2+}+\mathrm{H}_{2} \mathrm{O}_{2} \rightarrow \mathrm{Fe}^{3+}=\mathrm{OH}^{-}+\mathrm{OH}$

E. coli can eliminate substrates of the Fenton reaction by assimilating ferrous ions and biosynthesizing enzymes that catalyze hydrogen peroxide $\left(\mathrm{H}_{2} \mathrm{O}_{2}\right)$ decomposition to oxygen and water $[8,9]$. E. coli uses numerous systems to uptake iron. In the cytoplasmic membrane, the FeoB protein, encoded by $f e o B$ gene, is the primary transmembrane transporter of $\mathrm{Fe}^{2+}$ of E. coli [10]. Additionally, E. coli excretes siderophores, which are ferric iron $\left(\mathrm{Fe}^{3+}\right)$ chelating compounds. Nearly all E. coli strains produce enterobactin, which is one of the most effective siderophores. The synthesis of enterobactin receptor protein is dependent on the gene $f e p A$. The receptor proteins for salmochelins (glycosylated forms of enterobactin) are synthesized with iron $N$ gene contribution. The fhuA, fecA, fyuA, and iutA genes contribute to the biosynthesis of the following siderophores: ferrichromes (hydroxamate), rhizoterins (alpha-hydroxycarboxylates), yersinibactins (phenolate), and aerobactins (mixed-hydroxymate derivatives), respectively $[11,12]$.

Hydroperoxidases (catalases) limit ROS accumulation and, thus, are an integral component of how bacterial cells respond to oxidative stress. E. coli produces two types of hydroperoxidases, catalase/peroxidase I (HPI) and hydroperoxidase II (HPII), encoded by $k a t G$ and $k a t E$, respectively. HPI and HPII have different structures and kinetic properties. HPI has a minor hydroperoxidase activity in the total activity of catalase, however, it is the most important component of the bacterial resistance to $\mathrm{H}_{2} \mathrm{O}_{2}$. HPI possesses both catalase and peroxidase activity, unlike HPII. The active center of each hydroperoxidase contains a heme system with an iron molecule inside. The presence of iron is essential to the biosynthesis of the active form of both HPI and HPII [13].

We investigated mechanisms by which $E$. coli may influence chronic intestinal inflammation. Specifically, we raised a question whether $E$. coli induces the attenuation of inflammation by eliminating substrates of the Fenton reaction. We aimed to: (1) detect genes that facilitate iron ion acquisition (feoB, fepA, fhuA, fecA, iroN, fyuA, iut $A$ ), (2) establish whether the growth rate of $E$. coli increases in media supplemented with $\mathrm{Fe}^{2+}$, (3) compare catalase activity by assaying the kinetics of $\mathrm{H}_{2} \mathrm{O}_{2}$ decomposition in media with and without $\mathrm{Fe}^{2+}$ supplementation, and (4) investigate the influence of $\mathrm{Fe}^{2+}$ on the expression of the catalase genes katG and katE, produced by $E$. coli strains.

\section{Methods}

\section{Bacterial strains}

Ten E. coli strains were isolated from the inflamed colonic mucosa of 10 adult patients in the acute phase of UC, which was confirmed by severe endoscopic changes in their colon. Severity of symptoms in the patients was also determined on the basis of the Mayo Clinic disease activity index [2]. Biopsies were obtained during colonoscopy procedures carried out at the Clinic of Gastroenterology of the Jagiellonian University Medical College in Krakow, Poland, after approval by the Jagiellonian University Bioethical Committee (no. KBET/75/B from 15.11.2007). Informed consent was obtained from all patients participating in the study.

All subjects underwent the same type of preparation prior to colonoscopy, with oral sodium phosphate at a dose of $0.6-0.8 \mathrm{ml} / \mathrm{kg}$ (up to $45 \mathrm{ml}$ ) and bowel cleansing, consisting of four saline enemas. During colonoscopy, patients received intravenous sedation or general anesthesia, as required. The biopsy samples were taken with sterile tools with extreme caution for sterility by staff. The samples were placed in sterile tubes, suspended in Schaedler broth (SAB; Difco, USA) with $10 \%$ glycerol and stored at $-20{ }^{\circ} \mathrm{C}$ for up to 1 week. Biopsy samples were transported to the laboratory Department of Microbiology, Jagiellonian University Medical College on dry ice.

Frozen samples were thawed and homogenized in $1 \mathrm{ml}$ of Schaedler's medium (Oxoid, Hampshire, UK). Different media were used to cultivate bacteria under aerobic and anaerobic conditions to analyze the samples quantitatively for the main bacterial constituents [14].

Methods of preparing samples and media used for cultivation of particular groups of bacteria, were described in our previous paper [15].

Phenotypic identification of E.coli isolates from McConkey Agar was conducted with the commercial identification system API20E (BioMerieux, Marcy l'Etoile, France). To confirm the species designation, all isolates of Gramnegative rods were tested using the PCR method with species-specific primers for $E$. coli [16]. Stock cultures of the isolated strains were preserved at $-80^{\circ} \mathrm{C}$ on glass beads in BBL nutrient broth with $15 \%$ glycerol (BD). Ten E. coli strains randomly selected from our collection were included in the study (Table 1).

\section{Detection of genes encoding catalases and iron acquisition proteins}

PCR was used to detect: $k a t G$ and $k a t E$, which encode enzymes that catalyze $\mathrm{H}_{2} \mathrm{O}_{2}$ decomposition; $f e o B$, which encodes a $\mathrm{Fe}^{2+}$ transporter protein; fepA, fhuA, fecA, iroN, fyuA, iutA, which encode siderophore receptors. Primer sequences and amplification product sizes are shown in Table 2. 
Table 1 List of E. coli strains (EC1-EC10) used in the experiment. Species identification was conducted with the API 20E system. PCR was used to confirm the presence of genes encoding catalases (katG and katE), a ferrous transporter (feoB), and receptor proteins for siderophores (fepA, fhuA, fecA, iroN, fyuA, and iutA)

\begin{tabular}{llllllllll}
\hline E. coli & \multicolumn{9}{l}{ Gene presence } \\
\cline { 2 - 10 } $\begin{array}{l}\text { strain } \\
\text { number }\end{array}$ & katE & katG & feoB & fepA & fhuA & fecA & iroN & fyuA & iutA \\
\hline EC1 & $1+$ & $1+$ & $1+$ & $1+$ & $1+$ & $1+$ & $1+$ & $1+$ & $1+$ \\
EC2 & $1+$ & $1+$ & $1+$ & $1+$ & $1+$ & $1-$ & $1+$ & $1+$ & $1+$ \\
EC3 & $1+$ & $1+$ & $1+$ & $1+$ & $1+$ & $1-$ & $1-$ & $1-$ & $1-$ \\
EC4 & $1+$ & $1+$ & $1+$ & $1+$ & $1+$ & $1-$ & $1-$ & $1-$ & $1-$ \\
EC5 & $1+$ & $1+$ & $1+$ & $1+$ & $1+$ & $1-$ & $1-$ & $1-$ & $1-$ \\
EC6 & $1+$ & $1+$ & $1+$ & $1+$ & $1+$ & $1+$ & $1+$ & $1+$ & $1-$ \\
EC7 & $1+$ & $1+$ & $1+$ & $1+$ & $1+$ & $1+$ & $1+$ & $1+$ & $1+$ \\
EC8 & $1+$ & $1+$ & $1+$ & $1+$ & $1+$ & $1+$ & $1-$ & $1+$ & $1+$ \\
EC9 & $1+$ & $1+$ & $1+$ & $1+$ & $1-$ & $1-$ & $1-$ & $1-$ & $1-$ \\
EC10 & $1+$ & $1+$ & $1+$ & $1+$ & $1+$ & $1-$ & $1-$ & $1-$ & $1-$ \\
\hline
\end{tabular}

\section{Influence of $\mathrm{Fe}^{2+}$ on the growth rate of $E$. coli}

The $10 \mathrm{E}$. coli strains were grown overnight at $37{ }^{\circ} \mathrm{C}$ in McConkey agar (Oxoid). Each strain was inoculated in $10 \mathrm{ml}$ of tryptic soy broth (TSB) (BD) and incubated at $37{ }^{\circ} \mathrm{C}$ for $3 \mathrm{~h}$. After incubation, probes were microcentrifuged (5000 rpm, $10 \mathrm{~min}, 4^{\circ} \mathrm{C}$ ), supernatants were removed, and pellets were resuspended in $10 \mathrm{ml}$ of phosphate buffered saline (PBS). This step was repeated three times. Subsequently, each sample was diluted 1:3 in PBS. Bacterial density in prepared samples was determined by measuring optical density (JASCO Corporation Spectra Manager v.1.30.01) at a wavelength of $600 \mathrm{~nm}\left(\mathrm{OD}_{600}\right)$ in triplicate. Inoculums of the $E$. coli strains had a similar OD reading $0.5 \pm 0.02$, (equivalent to $1 \times 10^{5}$ colony forming units $/ \mathrm{ml}$ ).

From this culture, $100 \mu \mathrm{l}$ of bacterial inoculum were added to $10 \mathrm{ml}$ of one of four growth media: M9(-), $\mathrm{M} 9\left(\mathrm{Fe}^{2+}\right)$, TSB, or PBS. Defined minimal medium (M9(-)) consisted of $15.2 \mathrm{~g}$ of $\left(\mathrm{Na}_{2} \mathrm{HPO}_{4}\right) 12 \mathrm{H}_{2} \mathrm{O}, 3 \mathrm{~g}$ of $\mathrm{KH}_{2} \mathrm{PO}_{4}$, $0.5 \mathrm{~g}$ of $\mathrm{NaCl}, 1 \mathrm{~g}$ of $\mathrm{NH}_{4} \mathrm{Cl}, 0.0015 \mathrm{~g}$ of $\left(\mathrm{CaCl}_{2}\right) 2 \mathrm{H}_{2} \mathrm{O}$, $1 \mathrm{ml}$ of $1 \mathrm{M}\left(\mathrm{MgSO}_{4}\right) 7 \mathrm{H}_{2} \mathrm{O}, 1 \mathrm{ml}$ of $0.1 \mathrm{M} \mathrm{CaCl}_{2}, 10 \mathrm{ml}$ of $20 \%$ glucose, and $1000 \mathrm{ml}$ of $\mathrm{H}_{2} \mathrm{O}$. To remove iron from the medium, Chelex 100 (BioRad, Hercules, USA) was used in accordance with the manufacturer's instructions. Defined minimal medium supplemented with ferrous ions $\left(\mathrm{M} 9\left(\mathrm{Fe}^{2+}\right)\right)$ consisted of M9 minimal medium with $0.2 \mathrm{mM}\left(\mathrm{FeSO}_{4}\right) 7 \mathrm{H}_{2} \mathrm{O}$, stabilized with $0.3 \mathrm{mM}$ EDTA. TSB was used as the positive, while PBS as the negative control.

To follow bacterial growth, the $\mathrm{OD}_{600}$ was measured every $2 \mathrm{~h}$ for $12 \mathrm{~h}$. The last measurement was made after $24 \mathrm{~h}$ of incubation at $37^{\circ} \mathrm{C}$.

\section{Impact of $\mathrm{Fe}^{2+}$ on the kinetics of $\mathrm{H}_{2} \mathrm{O}_{2}$ decomposition by E. coli}

The bacterial strains were cultured in $10 \mathrm{ml}$ of $\mathrm{M9}(-)$, $\mathrm{M} 9\left(\mathrm{Fe}^{2+}\right)$, TSB, or PBS for $24 \mathrm{~h}$ at $37^{\circ} \mathrm{C}$. Probes were microcentrifuged (5000 rpm, $10 \mathrm{~min}, 4{ }^{\circ} \mathrm{C}$ ) and diluted in $10 \mathrm{ml}$ of $\mathrm{PBS}$ to a final $\mathrm{OD}_{600}$ of $0.5 \pm 0.02$, (equivalent to $1 \times 10^{5}$ colony forming units $/ \mathrm{ml}$ ). Then, $100 \mu \mathrm{l}$ of the diluted bacterial culture were added to $10 \mathrm{ml}$ of M9(-), M9 $\left(\mathrm{Fe}^{2+}\right)$, TSB, or PBS. Immediately afterward, chemically pure $\mathrm{H}_{2} \mathrm{O}_{2}$ (Sigma-Aldrich) was added to each culture for a final concentration of $60 \mathrm{mg} / \mathrm{L}$. The culture was incubated at $37{ }^{\circ} \mathrm{C}$. The amount of $\mathrm{H}_{2} \mathrm{O}_{2}$ remaining in the test tube was determined every $10 \mathrm{~min}$ by using Analytical Merckoquant peroxide test strips (Merck, NJ, USA). Negative controls for each media type with added $\mathrm{H}_{2} \mathrm{O}_{2}$ and no $E$. coli were included.

\section{Catalase gene expression change in response to $\mathrm{Fe}^{2+}$}

The 10 E. coli strains were grown in $\mathrm{M} 9(-), \mathrm{M} 9\left(\mathrm{Fe}^{2+}\right)$ or TSB media, as described above. Cells were collected from two time points at an $\mathrm{OD}_{600}$ of approximately 0.6, 1.0 for M9(-), 0.6, 1.0 for $\mathrm{M9}\left(\mathrm{Fe}^{2+}\right)$ and $0.6,2.0$ for TSB. Total RNA was extracted with the RNeasy Mini Kit (Qiagen, Venlo, Holand), according to the manufacturer's

Table 2 Primers used in this study

\begin{tabular}{lll}
\hline Gene & Primers sequences & Product size [bp] \\
\hline i6S rRNA & 5'-GGG AGT AAA GTT AAT ACC TाT GC-3' 5'-CTC AAG CTT GCC AGT ATC AG-3' & 204 \\
katE & 5'-AAC GAG TGA GGC TाT ACC TGC-3' 5'-AAC CTG AAA CTC TGC ACA ACG-3' & 173 \\
katG & 5'-CTG CGT TT GAT CCT GAG TTC-3' 5'-GGC CCG ATG TAG CGA GAT T-3' & 137 \\
feoB & 5'-CGT GTA GGT AAC TGG GCT GGC-3' 5'-AGG TCT GCG ATG AGA TGG TGG-3' & 127 \\
fepA & 5'-AGC TGA CTG ACA GCA CCA TCG-3' 5'-CGG GAT GAT CGA CAA ACG GTC G-3' & 554 \\
fhuA & 5'-AGA CAC TAT CAC CGT TAC CGC TG-3' 5'- GCC GCG AAT GAT CAG GTG GTC-3' & 265 \\
fecA & 5'-AGG TTA ATA TCG CAC CGG GAT CG-3' 5'-ATG GCA TCC ATG TTG CCG AGC-3' & \\
fyuA & 5'-AAG TCA AAG CAG GGG TTG CCC G-3' 5'-GAC GCC GAC ATT AAG ACG CAG-3' & 565 \\
iutA & 5'-GCA GTA GGC ACG ATG TTG TA-3' 5'-TGA TTA ACC CCG CGA CGG GAA-3' & 667 \\
\hline
\end{tabular}


instructions. RNA was diluted in diethylpyrocarbonate treated water (A\&A Biotechnology, Gdynia, Poland), and $100 \mathrm{ng}$ aliquots were treated with RNase-free DNase (Sigma-Aldrich), in accordance with the manufacturer's instructions. Following treatment, $20 \mathrm{ng}$ of RNA were converted to cDNA using the M-MuLV reverse transcriptase (RT) synthesis system (Thermo Scientific, Waltham, MA, USA). Random hexamers supplied with the kit were used to initiate CDNA synthesis.

RT-PCR was carried out using a Real-Time PCR CFX96 thermal cycler (BioRad). Reactions were carried out with the SYBR Green PCR Master Mix (Sigma-Aldrich). Cycling parameters were optimized to ensure primer efficiency. Cycling parameters for kat $G$ and katE primers were $95{ }^{\circ} \mathrm{C}$ for $30 \mathrm{~s}, 60{ }^{\circ} \mathrm{C}$ for $1 \mathrm{~min}$, and $72{ }^{\circ} \mathrm{C}$ for $45 \mathrm{~s}$. All reactions were performed in triplicate; $16 \mathrm{~S}$ expression was used to normalize the results. To confirm that only products of interest were formed, the melting curve and product sizes of each reaction were analyzed. Relative levels of gene expression were calculated by the $2^{-\Delta \Delta \mathrm{Ct}}$ (comparative $\mathrm{Ct}$ ) method [17]. The $16 \mathrm{~S}$ gene was chosen as the loading control.

\section{Statistical analysis}

Statistical analysis was carried out using software packages: Access and Statistica.

Likelihood ratio and $\chi 2$ tests were used. A $p$-value $<0.05$ was considered statistically significant.

\section{Results}

Occurrence of genes encoding catalases (katG, katE) and iron acquisition proteins (feoB, fepA, fhuA, fecA, iroN, fyuA, iutA)

Using PCR, we examined the occurrence of genes encoding catalases and iron acquisition proteins in the 10 E. coli strains isolated from inflammatory sites of intestinal tissues from UC patients. A gene for a $\mathrm{Fe}^{2+}$ transporter protein $(f e o B)$, which contributes to ferrous acquisition, and genes encoding enzymes that catalyze $\mathrm{H}_{2} \mathrm{O}_{2}$ decomposition ( $k a t G$ and $k a t E$ ) were present in all investigated strains. Each $E$. coli strain had at least one gene encoding a siderophore receptor (fepA, fhuA, fecA, iroN, fyuA, iutA). The results are shown in Table 1.

\section{Influence of ferrous ions on $E$. coli growth rate}

We used $\mathrm{OD}_{600}$ measurements to detect whether E. coli grew differently in the presence or absence of $\mathrm{Fe}^{2+}$ in the compared media. All investigated strains of $E$. coli grew fastest in TSB (Fig. 1), which contains all of the necessary nutritive elements for growth and was included as a positive control. The presence of ferrous ions in the $\mathrm{M} 9\left(\mathrm{Fe}^{2+}\right)$ medium increased the E. coli growth rate compared to the M9(-) medium. Statistical analysis, profiled by quadratic equation $(\mathrm{R} 2=0,93 ; \mathrm{f}=1196,267 ; p<$
0,0001), confirmed that all 10 strains, E. coli cultured in $\mathrm{M} 9\left(\mathrm{Fe}^{2+}\right)$ reached the log phase of growth faster and had higher $\mathrm{OD}_{600}$ values after incubation for $24 \mathrm{~h}$ compared to $E$. coli cultured in M9(-).

\section{Influence of ferrous ions on kinetics of $\mathrm{H}_{2} \mathrm{O}_{2}$ decomposition by $E$. coli}

To understand the impact of ferrous ions on the activity of catalases produced by $E$. coli, we monitored the kinetics of $\mathrm{H}_{2} \mathrm{O}_{2}$ decomposition (Fig. 2). We observed statistically significant differences in the ability to convert $\mathrm{H}_{2} \mathrm{O}_{2}$ between strains cultured in $\mathrm{M9}(-)$ and $\mathrm{M} 9\left(\mathrm{Fe}^{2+}\right)$ media. E. coli strains incubated in $\mathrm{M} 9\left(\mathrm{Fe}^{2+}\right)$ decomposed $\mathrm{H}_{2} \mathrm{O}_{2}$ faster than strains incubated in $\mathrm{M} 9(-)$ ( $\mathrm{f}=$ $165.9024, p<0.0001)$. These results indicate that the presence of $\mathrm{Fe}^{2+}$ in growth media influences catalase activity.

\section{KatE and katG gene expression is upregulated in the presence of ferrous ions in growth media}

We used quantitative real-time PCR to examine catalase (katE and katG) genes expression in response to the presence of $\mathrm{Fe}^{2+}$ in growth media. The 16S gene was used as a reference to analyze the relative changes in $k a t G$ and $k a t E$ expression. The $k a t G$ expression was upregulated in all investigated $E$. coli strains cultured in $\mathrm{M} 9\left(\mathrm{Fe}^{2+}\right)$ compared to E. coli cultured in M9(-) in the logarithmic and stationary phases of bacterial growth (Fig. 3). However, katE expression was not dependent on the presence of iron ions.

\section{Discussion}

Increased knowledge of UC pathophysiology requires better understanding of how interactions among bacterial factors, host genetics, and the immune system result in chronic mucosal inflammation [3]. As the largest population of microbes in the human body, the gut microbiota, has been implicated in many aspects of UC $[5,18]$. Members of the Enterobacteriaceae family, especially E. coli, may play important roles in the pathogenesis of inflammatory bowel disease (IBD). There is substantial controversy regarding the abundance of $E$. coli in the colonic mucosa of UC patients. Earlier studies have demonstrated that patients with UC or Crohn disease have increased E. coli populations in the gut [19]. In our previous study on populations of E.coli present in colon of the UC patients we also noticed that as to compared to the control group, there was a significant increase in the number of $E$. coli bacteria at the site of inflammation in patients with UC [15]. On the other hand, several works have consistently reported no increase of E.coli numbers in UC patients with respect to healthy subjects [20]. Discrepancies may be explained by differences in the disease severity of the patients 

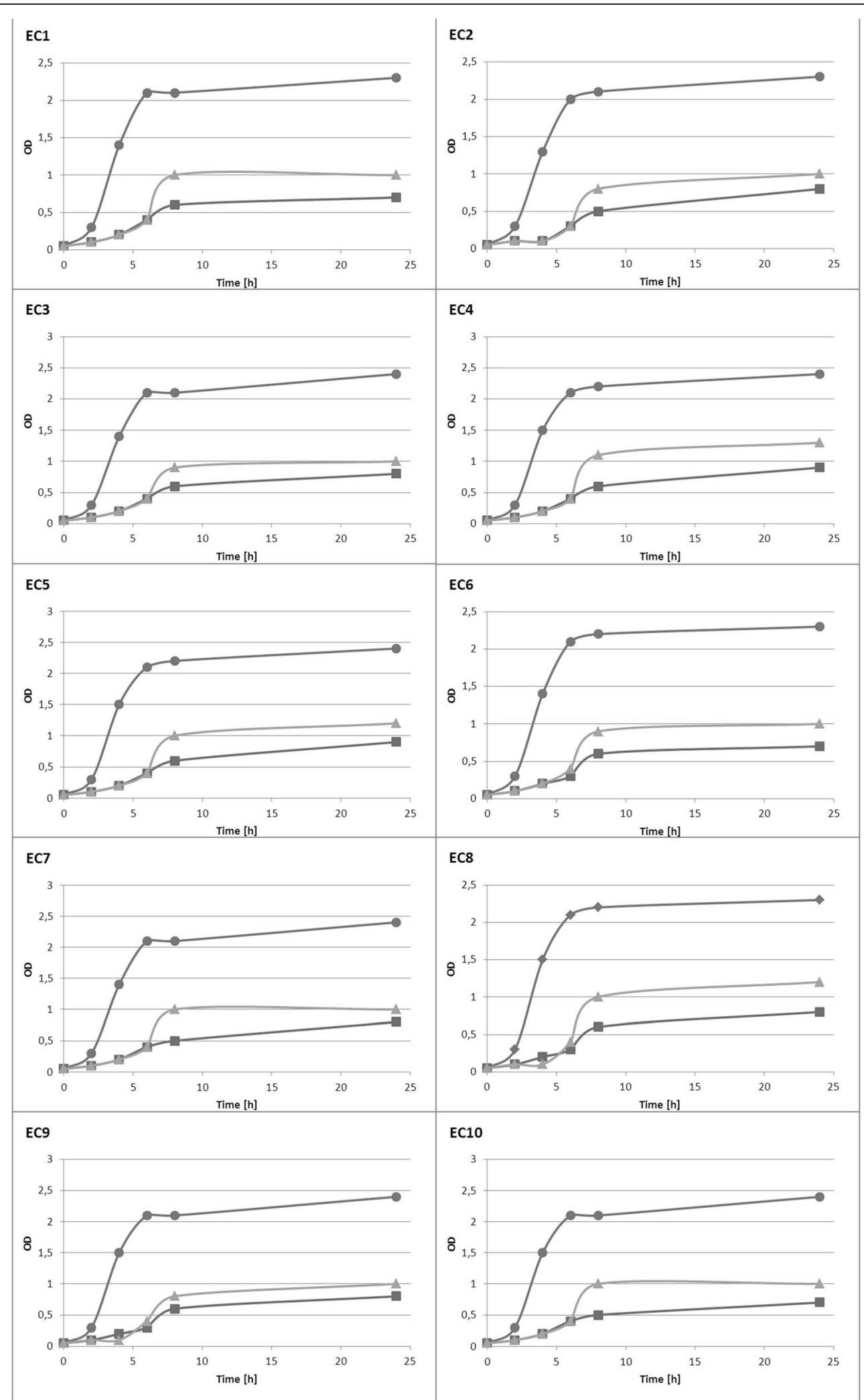

Fig. 1 Bacterial growth curves for the 10 investigated E. coli strains (EC1-EC10) in TSB media (circle), M9(Fe ${ }^{2+}$ ) media (triangle), and M9(-) media without iron ions (square) 

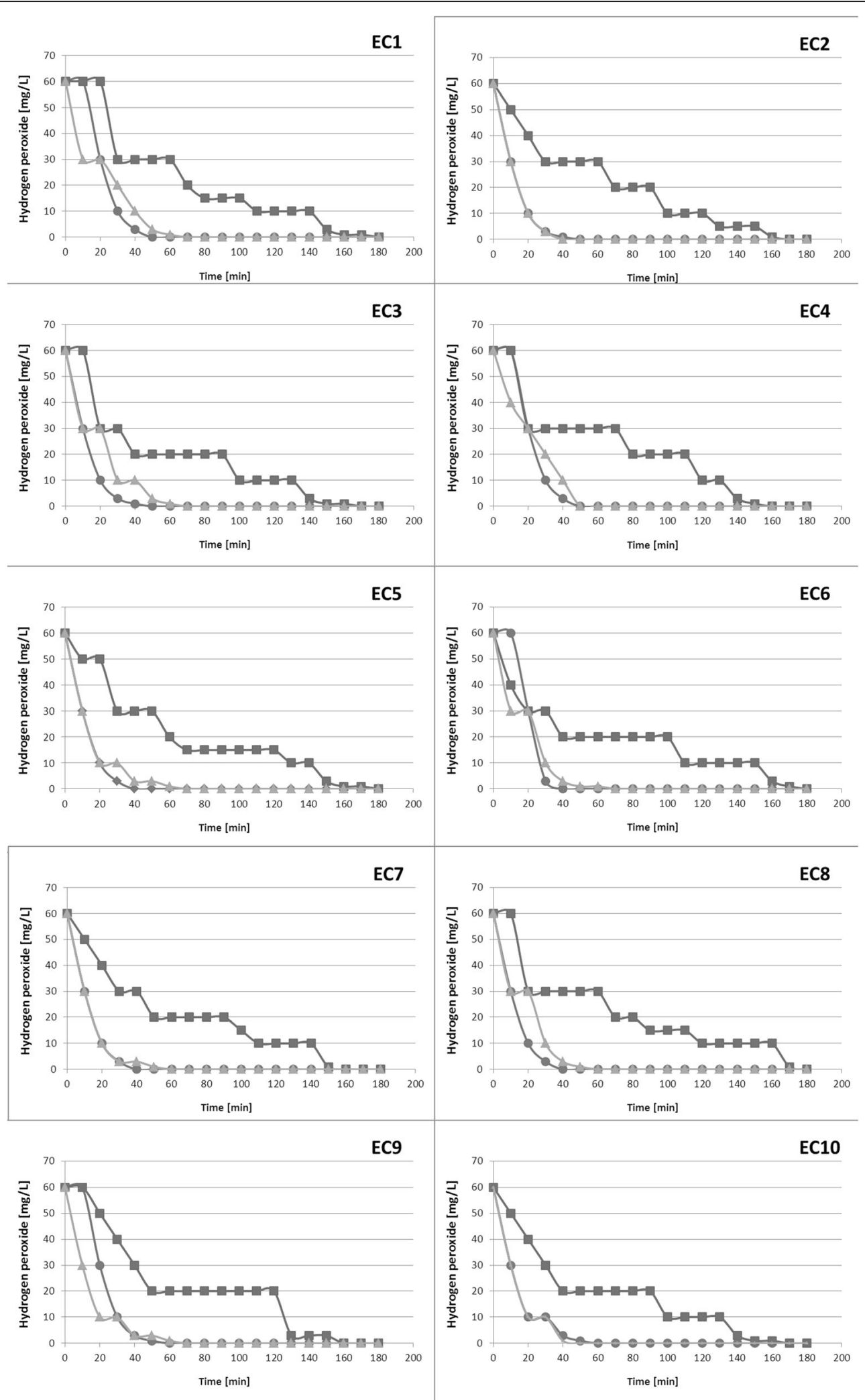

Fig. 2 Catalase activity for the 10 E. coli strains (EC1-EC10) in in TSB media (circle), M9(Fe ${ }^{2+}$ ) media (triangle), and M9(-) media without iron ions (sqare) 


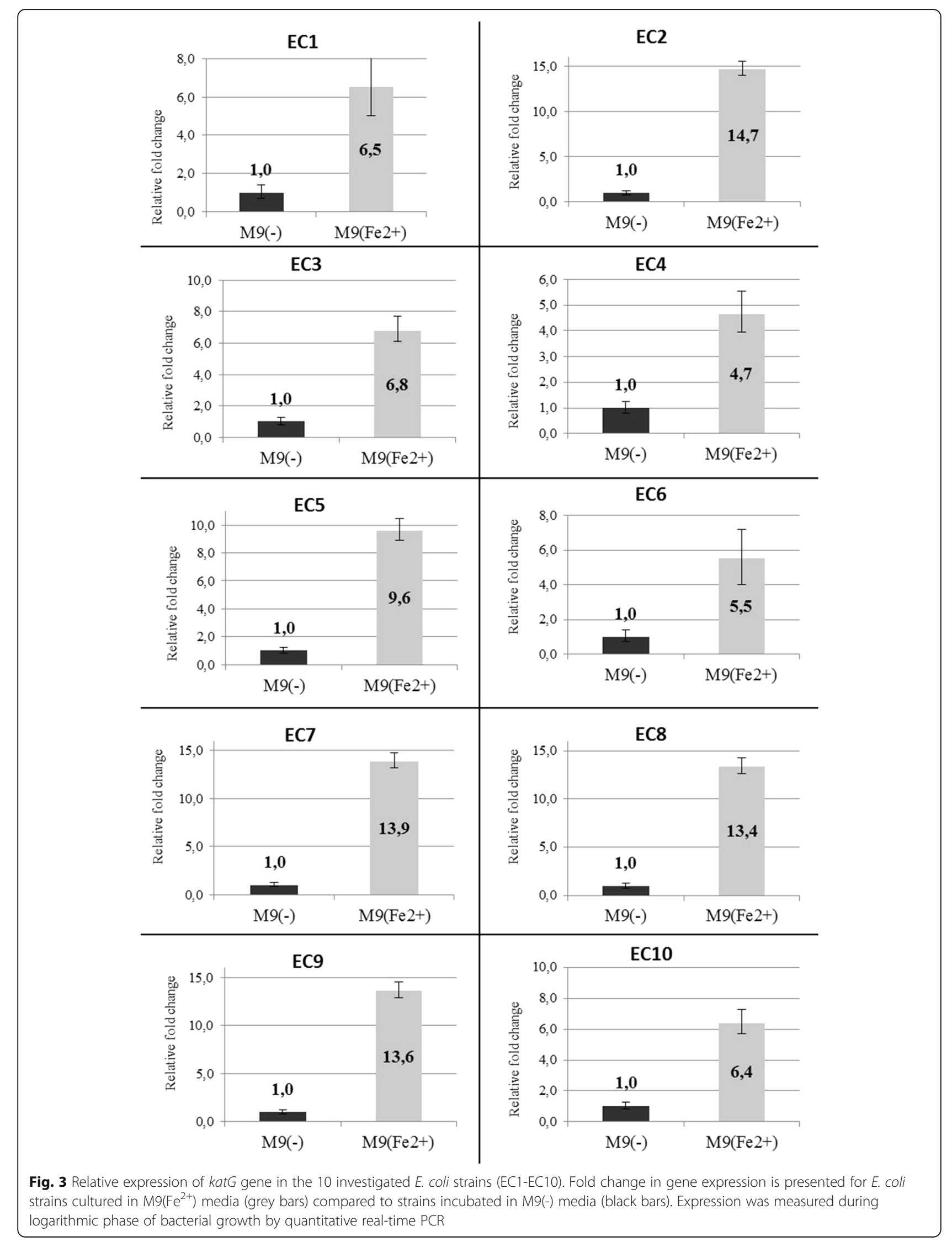


included to these studies and activity status in UC patients among study groups. Thus, the increase in numbers of E. coli may depend on different factors. Biofilm formation and the abilities to absorb ions and nutrients from the environment, but also on their abilities to breakdown ROS in the specific niche like as inflammatory site seem to most important $[11,21]$. Thus, the question arises: what is the role of $E$. coli population in course of UC? The standard opinion is that E. coli may contribute to the propagation of the chronic inflammation in UC by activating the local immune system. However, on the other hand, the increased numbers of $E$. coli in consequence intensify iron acquisition and catalase activity and on that way may prevent the Fenton reaction and, thus, induce remission of UC.

In this work, we aimed to identify pathways on which E. coli may be involved in the induction and/or maintenance of UC remissions. Hypotheses about the effect of probiotic E. coli strain on the health of patients in the acute phase of UC by inducing remission of the inflammatory process was raised by Seksik [22].

In our previous studies we have not only quantitatively assessed E. coli in UC patients as against to a control group, but also analyzed the genetic traits of $E$. coli. We performed comparative analysis of $52 \mathrm{E}$. coli strains, using Pulsed-Field Gel Electrophoresis. On the basis of these results was selected 10 strains of $E$. coli. Described strains were isolated from 10 different patients with acute phase of UC and characterized by different pulsotypes. Analysis of 52 restriction patterns revealed high great genetic variability diversity among $E$. coli strains isolated from inflamed mucosa. Moreover, the local inflammation status was not related to colonization by a specific type of E. coli [19]. Thomazini et al. obtained similar results using enterobacterial repetitive intragenic consensus-PCR in an analysis of 131 E. coli strains isolated from IBD patients (including patients with UC) and a control group. No specific strain or group of $E$. coli strains correlated with UC, Crohn disease, or the control group [23]. Earlier, Sepehri and colleagues using multilocus sequence typing, made a comparison of $E$. coli strains isolated from IBD patients (including UC) with those from the control group. They identified three main groups of the bacteria, but did not find any relationship between strains and disease type [24]. Thus, as it has been demonstrated by several authors and us, no particular strain or group of $E$. coli strains is associated with UC or Crohn disease.

Inflammatory sites in the colon mucosa contain large amounts of $\mathrm{H}_{2} \mathrm{O}_{2}$ from the immune cell-initiated explosion of oxygen and high concentrations of $\mathrm{Fe}^{2+}$ from degraded heme molecules. Both $\mathrm{H}_{2} \mathrm{O}_{2}$ and $\mathrm{Fe}^{2+}$ are substrates for the Fenton reaction, which produces the most active of all oxygen forms, the hydroxyl radicals
[25]. Hydroxyl radicals can react with almost all substances and can cause the peroxidation of lipids, the disruption of cell membranes, and the inhibition of enzymes that transport $\mathrm{Ca}^{2+}$ and $\mathrm{Mg}^{2+}$ ions across membranes $[9,11,26]$. For most microbes, iron is an essential element involved in multiple metabolic processes, including respiration and critical enzymatic reactions. It is difficult for bacteria that colonize the human GI tract, such as E. coli, to obtain enough iron for their metabolism. Therefore, bacteria have developed several systems to allow the absorption of $\mathrm{Fe}^{2+}$ and $\mathrm{Fe}^{3+}$, as well as to acquire iron by destruction of hemoglobin $[11,12]$. We sought to determine whether the number of genes that regulate iron acquisition in E. coli (fepA, fhuA, fecA, iroN, fyuA, and iutA) influences the growth rate of a bacterial population. These genes are involved in the biosynthesis of transporter proteins for several siderophores [11]. Regardless of the number of iron acquisition genes in their genomes, all $E$. coli strains grew significantly faster in the presence than in the absence of $\mathrm{Fe}^{2+}$. Thus, it appeared that any product of each of the detected genes may compensate for the absence of other proteins. Notably, all of the tested E. coli strains had the $f e o B$ gene, which biosynthesizes a protein that directly transports $\mathrm{Fe}^{2+}$ into the periplasm. Therefore, at inflammatory sites, E. coli may act as a specific chelator, or iron ion catcher, of both the second and third oxidation states of iron. It has been demonstrated that an excess of the soluble iron given orally has been related to deleterious changes to the gut microbiota in gastrointestinal diseases. and with increased growth and adherence of the enteric pathogens [27], while specific iron chelators have been proposed to inhibit the Fenton reaction and to improve the health status of patients with UC [25]. More recently, Werner and colleagues [28] demonstrated that depletion of iron in the gut prevented development of chronic inflammation in a murine model of Crohn's disease. It may be possible to use E. coli in a similar way as an iron-chelating agent in chronic inflammation.

In the acute phase of UC, the activity of an increased number of ROS intensifies the necrotic processes of the intestinal epithelium. E. coli may eliminate Fenton reaction substrates by biosynthesizing enzymes that catalyze $\mathrm{H}_{2} \mathrm{O}_{2}$ decomposition to oxygen and water. E. coli produces two inducible hydroperoxidases, HPI and HPII, which differ in structure and kinetic activity [29]. We tested whether $E$. coli strains isolated from patients in the acute phase of UC produced these catalases. All E. coli strains had both the HPIencoding katG gene and the HPII-encoding katE gene. When cultured in TSB media, all strains were able to decompose $\mathrm{H}_{2} \mathrm{O}_{2}$. The presence of $\mathrm{Fe}^{2+}$ in the culture media accelerated $\mathrm{H}_{2} \mathrm{O}_{2}$ decomposition by the $E$. coli strains compared to the culture medium without iron supplementation. Accordingly, we hypothesize that $E$. coli strains that 
cannot biosynthesize the active form of catalases would be unable to colonize the gastrointestinal tract of patients in the acute phase of UC because the oxidative stress level would be too high for them.

Next, we determined the $k a t G$ and $k a t E$ gene expression levels in response to the presence of elevated $\mathrm{Fe}^{2+}$ concentrations in the media. Real-time PCR revealed that $\mathrm{Fe}^{2+}$ induces $k a t G$ gene expression. In all tested $E$. coli strains, in the logarithmic and stationary growth phases, the $k a t G$ expression level was highest in media with $\mathrm{Fe}^{2+}$. Notably, we observed a 15 -fold increase in kat $G$ gene expression for one $E$. coli strain incubated in $\mathrm{Fe}^{2+}$-enriched media as compared to M9(-). However, the presence of $\mathrm{Fe}^{2+}$ in the media did not affect the expression of katE in any of the tested E. coli strains. Literature data [13] indicate that gene expression katE depends on the growth stage of the the bacteria culture and is much higher during the stationary phase. In the acute phase of UC population of E.coli are predominantly maintained in logarithmic growth phase. On the base of our results, we can hypothesize that $E$. coli populations may participate in the rapid elimination of $\mathrm{Fe}^{2+}$ at sites of active inflammation. With an increase in the $E$. coli numbers, there would be an increased biosynthesis of enzymes catalyzing $\mathrm{H}_{2} \mathrm{O}_{2}$ and its decomposition to water and oxygen. In this way, E. coli may eliminate the two substrates of the Fenton reaction and, thus, induce the initiation or prolongation of remission stages of UC (Fig. 4). It is of interest that long before contemporary studies on a possible role for $E$. coli in ameliorating clinical course of IBD, researchers had proposed the use of E. coli strain Nissle 1917 as a probiotic to improve the course of the disease. Clinical effects of using this strain has been reported and it is considered to be the equivalent of mesalazine, a drug used to maintain remissions in UC patients $[6,30]$. It is, therefore, possible that one of the mechanisms of the inhibition of the inflammatory reactions in UC underlying natural or intentional presence of high E.coli numbers in the intestine of UC patients is related to inhibition of the Fenton reaction. Thus, it seems that there is a possibility that nonpathogenic $E$. coli strains will be used successfully as probiotics to induce and perpetuate remissions in UC. Such a hypothesis should be verified in a well-designed, longterm clinical studies in which the same patients receiving selected E.coli strain would be observed during active and quiescent phases of the disease in comparison to control subjects.

It should be noted, that presented experiments are beginning research on the role of microbiota in inflammatory processes associated with UC. In consideration should be taken role of other groups of bacteria mainly Enterococcus in the course of inflammatory bowel disease. Our study was also limited by a low numer of the samples taken from the eligible patients. Moreover, unfortunately, it was not possible to measure concentrations of iron ions and hydrogen peroxide at the site of inflammation during surgery, or colonoscopy. To better understand the conditions occurring at the site of inflammation, we should taking into account the

\section{Fenton reaction}

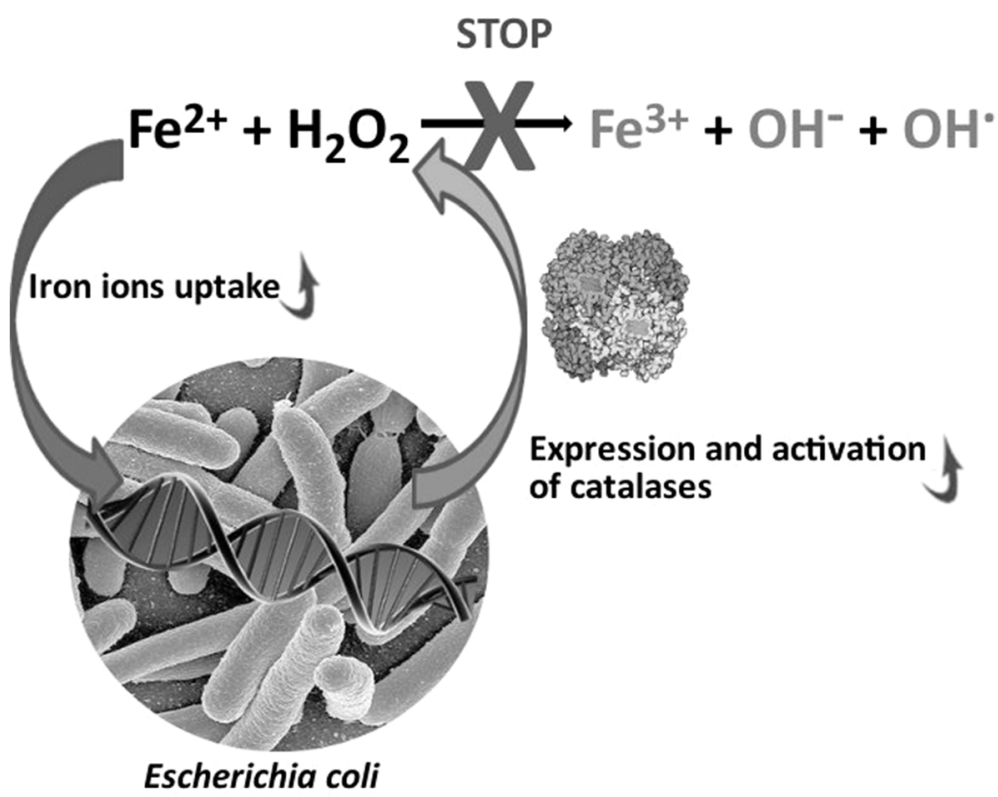

Fig. 4 Role of E. coli in inhibiting the Fenton's reaction 
proportion of cells of the immune system. This will provide a better model for in vitro studies.

\section{Conclusions}

More attention is devoted to the role of the E. coli in the inflammatory processes accompanying UC. On one hand, the numbers of the $E$. coli are significantly increased in inflamed colon, which may lead to the activation of the cells of the immunological system, whilst, on the other hand, the E. coli present the features which might affect the resolution of the inflammatory reactions in the intestines. In the acute phase of UC, necrotic processes of the intestinal epithelium are intensified as a result of the action of an increased number of reactive oxygen species. The E. coli may eliminate the substrates of Fenton's reaction by means of assimilating ferrous $\left(\mathrm{Fe}^{2+}\right)$ and by the biosynthesis of the enzymes catalysing the decomposition of oxygen peroxide. In this way, the E. coli may inhibit the formation of hydroxyl radicals, by which they may affect the initiation and/or prolongation of remission stages of UC.

\section{Abbreviations}

GI: Gastrointestinal tract; HPI and HPII: Hydroperoxidases; IBD: Inflammatory bowel diseases; PCR: Polymerase chain reaction; ROS: Reactive oxygen species; UC: Ulcerative colitis

Acknowledgements

Not applicable.

\section{Funding}

Supported by grants no. N N402 086134, N N401 144638, DEC-2013/09/B/ NZ6/00849 (The National Science Centre, Poland), KDSC/002107 (The Polish Ministry of Research and Higher Education).

\section{Availability of data and materials}

All the data supporting our findings is contained within the manuscript.

\section{Authors' contributions}

MPZ, MS: performed the laboratory section of the study; PA analyzed the data; PBH, MS, MPZ involved in writing and editing the manuscript. All authors read and approved the final manuscript.

\section{Authors' information}

Not applicable.

\section{Competing interests}

The authors declare that they have no competing interests.

\section{Consent for publication}

Not applicable.

\section{Ethics approval and consent to participate}

The study was approved by the Jagiellonian University Bioethical Committee (no. KBET/75/B from 15.11.2007). All patients have signed an informed consent form before inclusion.

\section{Author details}

${ }^{1}$ Department of Microbiology, Jagiellonian University Medical College, Czysta 18 Street, 31-121 Cracow, Poland. ${ }^{2}$ Polish Academy of Sciences, Institute of Nature Conservation, 33 Mickiewicza Avenue, 31-120 Cracow, Poland.

Received: 10 October 2015 Accepted: 16 June 2016

Published online: 10 October 2016

\section{References}

1. Ordas EL, Talamini M, Baumgart DC, Sandborn WJ. Ulcerative colitis. Lancet. 2012;380(9853):1606-19.

2. Sandborn WJ, Stenson WF, Brynskov J, Lorenz RG, Steidle GM, Robbins JL, Kent JD, Bloom BJ. Safety of celecoxib in patients with ulcerative colitis in remission: a randomized, placebo-controlled, pilot study. Clin Gastroenterol Hepatol. 2006;4(2):203-11.

3. Sartor RB. Mechanisms of disease: pathogenesis of Crohn's disease and ulcerative colitis. Nat Clin Pract Gastroenterol Hepatol. 2006;3(7):390-407.

4. Sasaki M, Klapproth J-MA. The role of bacteria in the pathogenesis of ulcerative colitis. J Signal Transduct. 2012;2012:704953.

5. Strus M, Gosiewski T, Fyderek K, Wedrychowicz A, Kowalska-Duplaga K, Kochan P, Adamski P, Heczko P. A role of hydrogen peroxide producing commensal bacteria present in colon of adolescents with inflammatory bowel disease in perpetuation of the inflammatory process. J Physiol Pharmacol. 2009;60 Suppl 6:49-54.

6. Sonnenborn U, Schulze J. The non-pathogenic Escherichia coli strain Nissle 1917-features of a versatile probiotic. Microbial Ecology in Health and Disease. 2009.

7. Simmonds N, Rampton D. Inflammatory bowel disease a radical view. Gut. 1993;34(7):865-8

8. Keshavarzian A, Banan A, Farhadi A, Komanduri S, Mutlu E, Zhang Y, Fields J. Increases in free radicals and cytoskeletal protein oxidation and nitration in the colon of patients with inflammatory bowel disease. Gut. 2003;52(5):720-8.

9. Lloyd RV, Hanna PM, Mason RP. The origin of the hydroxyl radical oxygen in the Fenton reaction. Free Radic Biol Med. 1997;22(5):885-8.

10. Cartron ML, Maddocks S, Gillingham P, Craven CJ, Andrews SC. Feotransport of ferrous iron into bacteria. Biometals. 2006;19(2):143-57.

11. Chu BC, Vogel HJ. A structural and functional analysis of type III periplasmic and substrate binding proteins: their role in bacterial siderophore and heme transport. Biol Chem. 2011;392(1-2):39-52.

12. Garénaux A, Caza M, Dozois CM. The Ins and Outs of siderophore mediated iron uptake by extra-intestinal pathogenic $<\mathrm{i}>$ Escherichia coli $</ \mathrm{i}>$ Vet Microbiol. 2011:153(1):89-98.

13. Schellhorn $\mathrm{H}$. Regulation of hydroperoxidase (catalase) expression in Escherichia coli. FEMS Microbiol Lett. 1995;131(2):113-9.

14. Conte MP, Schippa S, Zamboni I, Penta M, Chiarini F, Seganti L, Osborn J, Falconieri P, Borrelli O, Cucchiara S. Gut-associated bacterial microbiota in paediatric patients with inflammatory bowel disease. Gut. 2006;55(12):1760-7.

15 Pilarczyk-Zurek M, Chmielarczyk A, Gosiewski T, Tomusiak A, Adamski P, Zwolinska-Wcislo M, Mach T, Heczko PB, Strus M. Possible role of Escherichia coli in propagation and perpetuation of chronic inflammation in ulcerative colitis. BMC Gastroenterol. 2013;13(1):61.

16 Chiba N, Murayama SY, Morozumi M, Nakayama E, Okada T, Iwata S, Sunakawa K, Ubukata K. Rapid detection of eight causative pathogens for the diagnosis of bacterial meningitis by real-time PCR. J Infect Chemother. 2009;15(2):92-8.

17 Livak KJ, Schmittgen TD. Analysis of Relative Gene Expression Data Using Real-Time Quantitative PCR and the $2<$ sup $>-\Delta \Delta C T</$ sup $>$ Method. Methods. 2001;25(4):408-2.

18 Bringiotti R, lerardi E, Lovero R, Losurdo G, Di Leo A, Principi M. Intestinal microbiota: The explosive mixture at the origin of inflammatory bowel disease? World J Gastrointest Pathophysiol. 2014;5(4):550.

19 Martin HM, Campbell BJ, Hart CA, Mpofu C, Nayar M, Singh R, Englyst H, Williams HF, Rhodes JM. Enhanced $<\mathrm{i}>$ Escherichia coli $</ \mathrm{i}>$ adherence and invasion in Crohn's disease and colon cancer. Gastroenterology. 2004;127(1):80-93.

20 Martinez-Medina G-G. Escherichia coli in chronic inflammatory bowel diseases: An update on adherent invasive Escherichia coli pathogenicity. World J Gastrointest Pathophysiol. 2014;5(3):213-27.

21 Wohlgemuth S, Haller D, Blaut M, Loh G. Reduced microbial diversity and high numbers of one single Escherichia coli strain in the intestine of colitic mice. Environ Microbiol. 2009;11(6):1562-71.

22 Seksik P, Sokol H, Lepage P, Vasquez N, Manichanh C, Mangin I, Pochart P, Dore J, Marteau P. Review article: the role of bacteria in onset and perpetuation of inflammatory bowel disease. Aliment Pharmacol Ther. 2006;24(s3):11-8.

23 Thomazini CM, Samegima DA, Rodrigues MA, Victoria CR, Rodrigues J. High prevalence of aggregative adherent Escherichia coli strains in the mucosaassociated microbiota of patients with inflammatory bowel diseases. Int J Med Microbiol. 2011;301(6):475-9.

24 Sepehri S, Kotlowski R, Bernstein CN, Krause DO. Microbial diversity of inflamed and noninflamed gut biopsy tissues in inflammatory bowel disease. Inflamm Bowel Dis. 2007;13(6):675-83. 
25 Millar A, Rampton D, Blake D. Effects of iron and iron chelation in vitro on mucosal oxidant activity in ulcerative colitis. Aliment Pharmacol Ther. 2000;14(9):1163-8.

26 Baumgart DC, Sandborn WJ. Inflammatory bowel disease: clinical aspects and established and evolving therapies. Lancet. 2007;369(9573):1641-57.

27 Zimmermann MB, Chassard C, Rohner F, N'Goran EK, Nindjin C, Dostal A, Utzinger J, Ghattas H, Lacroix C, Hurrell RF. The effects of iron fortification on the gut microbiota in African children: a randomized controlled trial in Cote d'Ivoire. Am J Clin Nutr. 2010;92(6):1406-15.

28 Werner T, Wagner SJ, Martínez I, Walter J, Chang J-S, Clavel T, Kisling S, Schuemann K, Haller D. Depletion of luminal iron alters the gut microbiota and prevents Crohn's disease-like ileitis. Gut. 2010;2010:216929.

29 Hoerter JD, Arnold AA, Ward CS, Sauer M, Johnson S, Fleming T, Eisenstark A. Reduced hydroperoxidase (HPI and HPII) activity in the $\Delta<\mathrm{i}>$ fur $</ \mathrm{i}>$ mutant contributes to increased sensitivity to UVA radiation in Escherichia coli. J Photochem Photobiol B. 2005;79(2):151-7.

30 Kruis W, Schütz E, Fric P, Fixa B, Judmaier G, Stolte M. Double-blind comparison of an oral Escherichia coli preparation and mesalazine in maintaining remission of ulcerative colitis. Aliment Pharmacol Ther. 1997;11(5):853-8.

\section{Submit your next manuscript to BioMed Central and we will help you at every step:}

- We accept pre-submission inquiries

- Our selector tool helps you to find the most relevant journal

- We provide round the clock customer support

- Convenient online submission

- Thorough peer review

- Inclusion in PubMed and all major indexing services

- Maximum visibility for your research

Submit your manuscript at www.biomedcentral.com/submit 